\title{
Exporting Language Teaching Methods from Canada to China*
}

\author{
Gloria Paulik Sampson
}

\footnotetext{
ESL specialists at the present time have no conceptual framework to guide them in deciding whether teaching methods developed in one country are appropriate for the educational systems of other countries. Because of the lack of such a framework, three problems are emerging as Canadian and Chinese ESL specialists wrestle with the difficulties involved in exporting Canadian teaching methods to the People's Republic of China. These problems stem from not seeing development as multidimensional, from confusion about the relationship between scientific and educational theories, and from the worldwide presence and ac-
}

ceptance of technocratic imperialism. Some responses are suggested to the educational practices of modelling and memorization in China. It is suggested that these practices are not dysfunctional within the current educational theory in China that places high value on certain types of teacher-student interactions and on human interactions mediated by shared values which inhere in the canon of texts known as MarxismLeninism-Mao Zi-Dong thought. It is suggested that the teaching practices ESL teachers observe in China are not trivial or accidental, but inherent and important in the fabric of Chinese society.

\section{THE NEED FOR A FRAMEWORK}

When second or foreign languages are taught in a public school system, policy makers, whether they are in Canada or the People's Republic of China, face two questions. The first is which second or foreign languages should be taught in the public schools. The second is which methods of teaching should be used for these languages. These questions would appear to be straightforward ones. And perhaps they are in Canada, where both English and French are spoken natively by substantial portions of the population. Because large numbers of native speakers of both languages exist within Canada, it makes sense to teach both in the public schools and it seems obvious that those native speakers who teach the languages can develop whatever methods they feel are appropriate for use

* This article is a revised version of a paper presented at the TESL CAINADA Meeting at the Learned Societies Conference, University of British Columbia, May 1983. 
in the schools. But, in a country such as China, one of these questions is not quite so simple to answer. Chinese policy makers have answered the first question by selecting those indigenous second languages that promote the goal of social harmony. They have selected those foreign languages that they expect will promote technological progress. These are the major international languages such as English, French, German, Russian and Spanish. The second question is more difficult for policy makers in China to answer, especially with respect to the teaching of foreign languages. Should foreign methods be used to teach foreign languages?

It might be expected that once policy makers decide which languages should be taught in the schools, they only need to consult experts, such as applied linguists and educators, and these experts would provide state-ofthe-art information which would form the basis for appropriate teaching practices. But does there exist today a conceptual framework in which the task of adjusting teaching methods developed in one country to the needs of another country can be carried out? Unfortunately neither applied linguists nor educators have developed such a framework. Language experts, be they Chinese or Canadian curriculum developers, academics or teachers, have not yet developed a framework for systematically analyzing how to adapt teaching methods developed in one country to the conditions of another country. This problem of adaptation of methods is particularly acute when countries differ dramatically with respect to cultural values, economic organization, political system and historical patterns of development. That a conceptual framework is lacking is shown by the existence of three major problems that are emerging as Canadians attempt to export their language teaching methods to China and Chinese ESL specialists attempt to use these new imports.

These three problems have gone unnoticed by those involved in the field of teaching English as a second language. Why they have gone unnoticed will perhaps become apparent as they are discussed. Before examining these problems one by one, I shall first provide a brief sketch of all three.

The first problem stems from what might be called the fallacy of the unidimensionality of development. Briefly, so-called "developed" countries are accustomed to supplying finished products of a high technological nature to so-called "developing" countries. Somehow or other, the idea has arisen that everything a developed country exports to developing countries is necessarily highly developed, including ideas, as well as manufactured products. I wish to suggest that we need to distinguish between technological development and social development, and that a country which is highly developed technologically is not necessarily highly developed socially. This difference between technological development and 
social development impacts upon education because education is not a technological domain, but a social domain. There has been an attempt in some countries, most notably the United States, for some academics to claim that education is essentially part of the technological domain. I suggest that this claim is false. The claim has achieved widespread support in the U.S., as opposed to European countries, because educational methods arising from such an approach can be used for political ends.

The second problem arises from a confusion current in western thinking relating to the similarities and differences between scientific theories and educational theories. I shall suggest that there are profound differences between scientific theories and educational theories. Language educators and linguists need to clarify whether they are exporting or importing a method of language teaching which has a scientific base or an educational base.

The third problem stems from technocratic imperialism. This is a form of export of intellectual goods which claims to be value-free and therefore the goods are deemed appropriate for all countires. These intellectual goods are, however, laden with cultural and political values.

If positive intellectual and educational exchanges between Canada and the People's Republic of China are to continue, then academics and teachers in ESL on both sides must be aware of these three sources of potential difficulty. If Chinese and Canadian academics and teachers remain unaware of these problems, disillusionment and disappointment will be the bitter fruits of educational exchanges. To some extent this can be seen happening already. Some Canadian teachers returning from China have stated that they felt that all their Chinese students wished to do in their ESL classes was to memorize. And Chinese ESL teachers have complained that there are just too many new and different methods for teaching English and no criteria for choosing among them, except perhaps one's emotional proclivity towards one or the other. And in a country such as China with an intellectual tradition stemming from ancient times, emotional proclivity is not seen as an appropriate way of dealing with major educational decisions.

\section{THE FIRST PROBLEM}

Consider now the first source of difficulty-the notion that development is unidimensional. The problem arises from the fact that educators in technologically developed countries assume that the teaching methodologies they develop are exportable in the same way that the technologies of these countries are exportable. If there is a difficulty with the way 
that an advanced technology is used in a Third-World country, it is assumed that it is not the technology that is at fault, but the unreadiness of that country to receive that technology. The Third-World country is told to upgrade itself in order to prepare itself to receive that advanced technology. Normally this requires the creation of an appropriate infrastructure. In education this may entail the complete retraining of teachers. The teachers are told the methodologies they are using are old-fashioned and therefore should be replaced. Teachers in Third-World countries have usually accepted such prescriptions from Western specialists. These countries are poor, those doing the prescribing are rich, and surely the rich countries must be right.

An alternative hypothesis of development can be considered however. Suppose that there are two dimensions of development (there are perhaps even more than two): the technological dimension and the social dimension. Perhaps a country could be technologically advanced and socially backwards (or vice versa). So, for instance, what a country could export technologically might be worth taking, but what it exports on the social dimension might be not worth taking at all. The most vivid instance historically of such a country would be Nazi Germany in this century. Germany of the late 1930's was one of the most advanced nations technologically in the world. But contrast its technological development to its social development. What social structures, what educational ideas did Nazi Germany export? Were those structures and those educational ideas socially developed or socially backwards? Other more detailed examples can be provided for today's world.

Consider domains in which countries vary in social development, such as education, health care, care of the aged, and the like. Development across such domains in specific countries might be quite uneven. The domain of health care is instructive. A country could have the most advanced medical technology in the world, and yet there might not be universal access to health care in that country. In such a case, it is clear that in the domain of health care, the country would be highly advanced technologically, but backwards socially.

The examples above suggest that it makes sense to distinguish between technological and social advancement or backwardness. Furthermore, both technological and social development can be analyzed domain by domain. Given this multidimensional analysis of the concept of development, ESL specialists must take care that they do not make the mistake of labelling a country with a unidimensional label of advanced or backwards. Canadian ESL specialists must begin to consider the question of whether they are offering technological assistance or social assistance. To answer this question, ESL specialists must decide to what extent the 
methods they export have a scientific base or to what extent they have an educational base.

\section{THE SECOND PROBLEM}

The second problem stems from a lack of clarity regarding the differences between scientific theories and educational theories. ESL specialists need to decide whether a teaching method is essentially a scientific phenomenon or an educational phenomenon. Do the ESL methods being exported to China have primarily a scientific/technological base or do they have an educational base?

In 1966 the eminent linguist Noam Chomsky advised foreign language teachers to be "skeptical about the significance, for the teaching of languages, of such insights and understanding as have been attained in linguistics and psychology." Chomsky was wise to provide this advice, but he gave teachers the wrong reasons to be skeptical. He said that teachers should be skeptical of the findings of linguistics and psychology because the foundations of those sciences appeared to be shaky. Even if the foundations of those sciences were quite solid, however, the significance for education would still be open to question. Why? To arrive at an answer to this question, the educator and the linguist or psychologist need to understand the differences between sciences such as linguistics and psychology on the one hand and the discipline of education on the other.

The most important difference between an educational theory and a scientific theory, such as a linguistic or psychological one, is that an educational theory is laden with values, whereas a scientific theory is value-free (Egan, 1983). The goals of a scientific theory are primarily to amass knowledge and to explain the facts amassed. A scientific theory proposed to explain some set of facts will be accepted by the scientific community if the theory is concise, logical, and can explain interrelationships among the facts. In contrast, the goals of an educational theory are quite different. An educational theory is a guide to the actions required to produce a certain kind of person. The acceptability of an educational theory is dependent upon how well that theory works in helping human beings to become like the kind of person specified in the goal. The goal may be as straightforward as "the learner will be able to read silently and understand with $90 \%$ accuracy a manual in English outlining the maintenance of an electrical generator." Or the goal may be subject to widely varying interpretations, as in "the learner will emerge from Grade Twelve as a civic-minded citizen." Whatever the goal, the educator and the community make value judgments about it as well as about the specific 
educational process learners pass through in order to reach the goal.

Such value judgments do not figure in a scientific theory. Morphemes are not judged as good or bad. Indeed the layman is not even invited to make judgments within the framework of a scientific theory. Those who are specialists in a scientific field are alone felt qualified to decide on the theoretical acceptability of a linguistic concept such as morpheme or transformation. In contrast, however, the specialist alone does not determine what is acceptable in an educational theory. Because education is a social process, all persons in a society feel entitled to participate in assessing an educational theory. This fact explains why on any given day a person can pick up a newspaper in practically any country of the world and see editorial commentary or letters to the editor in which laypersons comment on the state of the educational system of the country.

These observations lead to the conclusion that an educational theory shares the attributes of a political or moral theory; one speaks of "good" or "bad" educational practices. And, of course, what is good or bad is always dependent on particular circumstances. What is good educational practice in Canada might be construed as bad in China, and vice versa. In sum, an educational theory is value-laden, whereas a scientific theory is value-free.

It is important to note that just because educational theory is valueladen, its importance and stature is in no way inferior to that of the value-free theories of the sciences. Educational theory, like scientific theory, needs to be logical, rational and systematic. Although educational theory differs qualitatively from scientific theory, it cannot be judged inferior to scientific theory.

Given the distinction between educational theory and scientific theory, what is the relationship between these two kinds of theories in the field of ESL pedagogy? Some ESL researchers, such as Dulay, Burt and Krashen (1982, pp. 261-269) appear to believe that their theories of how languages are learned should feed directly into educational practice. But, given the profound differences between scientific theory and educational theory outlined above, this cannot logically be the case. It is only educational theory that can feed directly into teaching practice and curriculum development. It has to be the case that the role of an educational theory is to interpret the applicability of findings in the sciences to educational practice. That is, an educational theory is used to judge the findings of scientific theories and assess whether particular scientific findings can in fact be applied to specific school settings without harming human beings. And it is precisely here that potential difficulties arise in the interactions between Chinese and Canadian ESL specialists, since each country will necessarily have developed its own theory of education. Scientific findings that are acceptable and useful within the context of one educational 
theory may be quite unacceptable within the context of another educational theory. One striking example of how scientific findings may be interpreted in two quite different ways is found when the notion of the "innate learning processors" (Dulay, Burt and Krashen, pp. 45-47, 54) is examined. The notion of innate learning processors has been developed by one group of ESL researchers to describe how second languages are learned. An educational evaluation of the scientific hypothesis will reveal whether or not the hypothesis has any relevance for an educational system.

\section{An Educational Theory Evaluates a Scientific Hypothesis}

What does the language educator do when confronted by various scientific hypotheses that may be relevant to the educational process? The first step the educator takes is to evaluate the hypothesis using the framework of an educational theory. The educational theory is not used to throw out scientific findings, but rather to decide which dimensions of a particular scientific theory are relevant to the specific conditions of the learners that the educator is dealing with. The educational theory is, of course, value-laden because any educational theory is necessarily based on a particular view of human nature and the socialization process.

In recent years, some psychologists, linguists and ESL researchers have explored the notion that language learning is primarily a biologicallygoverned process rather than an environmentally-governed one. Concepts such as the Innate Language Acquisition Device (McNeill, 1976), the Language-Responsible Cognitive Structure (Chomsky and Walker, 1978) and the Innate Learning Processors (Dulay, Burt and Krashen, 1982) have been proposed as mechanisms to explain how people learn first or second languages. These proposed mechanisms are essentially innate devices that automatically turn on shortly after birth, run until puberty when they shut off and somehow cause people to learn first or second languages. Whatever the details of the proposed mechanisms may be, the educator first notices that if linguistic structures somehow unfold through the mediation of such mechanisms, the process occurring is in fact not learning at all, but simply growth or development. Indeed, the ESL researchers who propose the existence of these innate learning processors themselves deny that learning plays any significant role and call the process they investigate language "acquisition," rather than language "learning." Learning, which equucators associate with conscious thought, rationality and reflection, is relegated to the sidelines by these researchers. Any educator working within the context of an educational theory which highlights self-awareness or consciousness, rationality and reflection is undoubtedly going to question seriously the appropriateness of teaching 
practices based on a scientific hypothesis which denies a major role to these processes.

When scientific hypotheses such as those of McNeill, Chomsky and Walker, and Dulay, Burt and Krashen emphasize the biological nature of language learning, they are difficult or impossible to use within an educational framework. For example, Dulay, Burt and Krashen inform teachers that students learn a second language primarily through "natural communication," that they learn most from their peers, and that correction of student errors is ineffective (pp. 261-263). The emphasis on socalled natural communication denies the efficacy of the classroom, for the classroom is an "unnatural" setting. But major educational theorists, such as John Dewey, have pointed out that for learning to occur, teachers must carefully craft the environment (Dewey, 1938; Sampson, Note 1). A "natural" environment is usually an ineffectual environment because it does not maximize the possibilities for learning to take place. The concept of "classroom" was developed by educators and intended to be unnatural because educators have known for years that random inputs do not lead to effective, efficient or comfortable learning for students. Educational research has shown for years that students do not learn most from their peers, but rather from adults. Consequently, intervention programmes for disadvantaged learners, as well as programmes for regular students, are based on low teacher-student ratios. Furthermore, the fact that teacher-student interaction leads to more effective learning has also been a tenet of effective educational theories as well as psychological ones (Vygotsky, 1972).

In sum, the scientific hypotheses that propose such mechanisms as the innate learning processors are not in accord with the research on which present-day educational theories are built. As a result, such scientific theories can only be regarded as irrelevant to educational practice.

This example of how educational theory evaluates scientific findings illustrates two points. The first is that different educational theories may evaluate the same findings differently. For instance, an educational theory that stressed the genetic differences among people might evaluate the innate learning processors hypothesis quite differently and might find the hypothesis useful. Second, information about the educational theory underlying the system of public education is necessary so that decisions can be made about how that theory will evaluate specific research findings in order to determine their applicability to educational practice. 


\section{THE THIRD PROBLEM}

The third problem manifests itself particularly when Canadian applied linguists or teachers introduce the newest methods of teaching in China. It is often suggested to the Chinese ESL specialists that the new methods being presented are wholly scientific. Sometimes they are proposed as a kind of modern technology of teaching. Because of this association of methods with modern technology (and hence science), both Canadian and Chinese ESL specialists unconsciously assume that the methods are value-free, and, as a result, applicable to all teaching situations. If Chinese ESL specialists express reservations about the new methods, it is sometimes assumed that they are unwilling to accept the latest scientific findings in ESL. And, what could be worse than to be unscientific in today's scientific world?

What forms does this being "unscientific" take? Some criticisms of teaching and learning practices in China are these:

(1) There is an excessive focus on memorization;

(2) There is an excessive focus on reading and a concommitant lack of emphasis on communicative activities in the classroom;

(3) Classes are teacher-centred rather than learner-centred.

Now the key question here is whether these differences between Canadian educational practices and Chinese educational practices are due to China being backwards technologically or due to differences related to contrasting educational aims in the two countries. That is, can these differences in educational practice in the two countries be traced back to scientific theories (or the lack of them) or to differing educational theories.

At this point, perhaps the basic argument should be recapitulated. First, ESL specialists must distinguish between scientific theories and educational theories. After the differences between these two kinds of theories are made clear, it can be seen that only an educational theory can provide input directly into the language teaching classroom or into curriculum development. This is so because education has specific value-laden goals. But, it seems to be the case in today's world that concepts and procedures that are value-laden are being exported under the guise of being value-free, that is being scientific. Specifically, educational practices in ESL are being exported that claim to be scientific, and therefore usable under circumstances that are quite different from those in which they were originally developed.

In short, I am suggesting that a teaching method cannot be wholly or perhaps "simply" scientific. Therefore, methods cannot be exported with the notion that they are universally appropriate. Since every teaching 
methodology contains an inherent set of values, ESL specialists must tease out the values that are in the methods they use so that these values can be compared with those in the educational system of the country which is considering adopting the method. If the values are congruent, then the method will be usable within the educational system. If the values inherent in the new method conflict with those in the educational philosophy of the country, then it is only to be expected that the proposed method will be unsuitable for adoption.

Let us now examine two key concepts which pervade educational theory in the People's Republic of China and consider the question of whether new methods of teaching ESL which have been proposed by Canadian ESL specialists will be congruent with the theory of education in use in China.

\section{EDUCATIONAL THEORY IN CHINA}

The first key factor pervading educational theory in China is the concept of modelling. The notion of the teacher as a model has played a role since ancient times in Chinese educational theory. The notion of model is a complex one in educational theory and must not be confused with the notion of authoritarianism. Chinese students take their teachers as models, but do not necessarily thereby imbue them with authority. For instance, Han Yu (768-824 A.D.) in On the Teacher stated that the pupil is not inferior to the teacher and the teacher is not necessarily superior to the pupil. Nor are teachers necessarily highly directive in their relationships with pupils. Liu Tsung-Yuan (773-819) in drawing an analogy between the cultivation of men and the cultivation of trees presents the words of a gardener: "I am by no means capable of making trees live long and flourish, but what I can do is to enable them to follow their natural propensities and evolve as nature wishes. When they are planted, trees should not be disturbed or worried over. When they are left behind, there is no looking back." While the student perceives the teacher as a model, the teacher takes care not to distort the development of the student through excessive external pressure in one direction or another. Although the teacher may be non-directive in general, it is also the teacher's responsibility to recognize the distinctive qualities, particularly those that are assets, of his or her pupils (Han Yu, The Thousand-li Horse) and to help the student develop those assets fully.

The second key factor is that not only is the teacher a model for the learner in the Chinese educational system, but the text is also a model for the learner. One obvious way of internalizing a textual model is, of course, 
to memorize. In the capitalist countries of the West, millions of tons of paper, print and ink pass daily through a cycle of instant obsolescence. So Westerners are accustomed to a massive structure of insignificance in print. The critic George Steiner in his essay Text and Context has pointed out, however, that societies based on Marxism-Leninism are "bookish to the root." He states, "The scheme of origins, authority and continuum in force in the Marxist world derives its sense of identity and its daily practices of validation or exclusion from a canon of texts" (p. 5). He goes on to say, "Arguments on literature, on the condition of the novel, on drama, are not academic or at the specialized margin of the life of feeling. They are conducted and felt to be at the core." In short, the text, the written word, has a value and has consequences in China far beyond anything North Americans can imagine in their own mercantile cultures. From the Chinese perspective, memorization is far from being an easy cop-out or a release from thinking. It is considered the initial step in assimilating a lesson. To know a text by memory first of all means that the text is important to the learner. To be able to recapitulate that text by memory means that the learner can play with it in his mind at will. Only after the text is internalized through memorization can it be considered the learner's text as well. So, memorization becomes an important first response to a text in a society which takes the written word seriously.

That Western teachers respond to memorization by Chinese students with such derision and scorn is, I venture to suggest, not a mark of advanced scientific thinking, but the response of persons raised in a society used to the instant obsolescence of words. Perhaps Westerners need to reflect carefully on this matter and ask why there is apparently nothing worth memorizing in Western society today. Are Western teachers responding sensibly and sensitively when they deride memorization in a population where it serves an important and valuable function?

It appears then that there is a hierarchy of values in a society based on Marxism-Leninism-Mao $\mathrm{Zi}$-Dong thought. Those values are shared through a canon of respected texts. The texts are re-examined, reevaluated and added to over time. Most importantly, at least from the perspective of a language teacher, the texts are remembered and remembered well, for they form the shared values of a coherent and powerful society. Could it be that Canadian teachers denigrate memorization which is the skill used by members of Chinese society to ensure societal coherence and continuity because Canadians, from a fragmented, noncontinuous society, do not undérstand, and perhaps even fear, this powerful mechanism for societal cohesion?

The Canadian specialist in the teaching of English as a foreign language is confronted then in China by an educational theory based on Marxism- 
Leninism-Mao Zi-Dong thought. Certain concepts, such as that of modelling and the authority of the written text, lead to particular educational practices. The two most obvious ones relate to certain kinds of teacherstudent interactions and the memorization of text. I have suggested that these practices are not trivial or accidental, but inherent and important in the fabric of Chinese society.

As Canadian ESL specialists carry new teaching methods to China and as Chinese ESL specialists consider whether to adopt or adapt these new methods, I hope a conceptual framework for analyzing new teaching approaches arises. The distinction I have made between scientific theories and educational theories reveals the fact that no teaching method can be value-free and hence no method can be universally applicable. I hope that ESL specialists can recognize that a country's being technologically advanced in certain domains does not ensure that it is also socially advanced in those domains. I hope that by viewing modelling and memorization not as mere isolated educational practices but as educational practices emerging from the fabric of society as a whole, it is apparent that methods of teaching developed in Canadian settings cannot be exported easily to other cultures where a different perspective of that eminently social process called "education" is in place.

\section{NOTES}

1. Sampson, G.P. Scientific Theory versus Educational Theory. Conference on New Approaches in Foreign Language Methodology (15th Colloquium of the Association Internationale pour la Recherche et la Diffusion des Méthodes Audio-Visuelles et Structuro-Globales), Sept. 6-9, 1983, Nijmegen, The Netherlands.

\section{REFERENCES}

Chomsky, N. Linguistic theory. In M. Lester (Ed.), Readings in applied transformational grammar. New York: Holt, Rinehart and Winston, 1970.

Chomsky, N. \& Walker, E. Introduction: The linguistic and psycholinguistic background. In E. Walker (Ed.), Explorations in the biology of language. Montgomery, Vermont: Bradford Books, 1978.

Dewey, John. Experience and education. New York: Collier Macmillan, 1938.

Dulay, H., Burt, M. \& Krashen, S. Language two. New York: Oxford Univeristy Press, 1982.

Egan, K. Education and psychology. New York: Teachers College Press, 1983.

Han Yu. On the teacher. In Shih Shun Liu (Ed.), Chinese classical prose. Hong Kong: Chinese University Press, 1979.

Han Yu. The thousand-li horse. In Shih Shun Liu (Ed.), Chinese classical prose. Hong Kong: Chinese University Press, 1979. 
Liu, Tsung-Yuan. The tree-planter, Ku the camel. In Shih Shun Liu (Ed.), Chinese classical prose. Hong Kong: Chinese University Press, 1979.

McNeill, D. Developmental psycholinguistics. In F. Smith \& G. A. Miller, (Eds.), The genesis of language. Cambridge Mass.: M.I.T. Press, 1966.

Steiner, G. On difficulty and other essays. Oxford: University Press, 1978.

Vygotsky, L.S. Mind in society. Cambridge, Mass.: Harvard University Press, 1978.

\section{THE AUTHOR}

Gloria Paulik Sampson is an Associate Professor in the Faculty of Education at Simon Fraser University in Burnaby, B.C. She received her doctorate in Theoretical Linguistics from the University of Michigan, Ann Arbor in 1969, specializing in English and Chinese linguistics. She is the author of the ESL series New Routes to English (Collier Macmillan Canada Ltd.). She spent the academic year 1980-81 teaching Applied Linguistics at the Guangzhou Institute of Foreign Languages in the People's Republic of China. 

VOL. 1, NO. 1, JAN 1984. 